\title{
Interannual winter temperature variability in the north of the Iberian Peninsula
}

\author{
J. Sáenz ${ }^{1, *}$, J. Zubillaga ${ }^{2}$, C. Rodríguez-Puebla ${ }^{3}$ \\ ${ }^{1}$ Depto. de Física Aplicada II and ${ }^{2}$ Depto. de Física de la Materia Condensada, Universidad del País Vasco, 46080 Bilbao, Spain \\ ${ }^{3}$ Depto. de Física de la Atmósfera, Universidad de Salamanca, 37008 Salamanca, Spain
}

\begin{abstract}
This work analyses the interannual variability of winter temperature in the north of the Iberian Peninsula. This area exhibits a different behaviour to the rest of the Iberian Peninsula, according to the loading factors of the leading empirical orthogonal function of Iberian winter temperature and precipitation. The regional time series is defined by means of principal components analysis (PCA) as a data reduction tool. The only significant eigenvalue can be related to synoptic causes. It is linked, for signals with a period lower than $10 \mathrm{yr}$, to the East Atlantic teleconnection pattern. It does not show any significant correlation to the North Atlanic Oscillation (NAO) or Arctic Oscillation (AO), which are the major factors controlling temperature over European or Iberian areas. This result agrees with previously published works and can be explained on the basis of enthalpy transport density vectors and geopotential anomaly over the area. Eddy terms do not play a significant role in this relationship. The link of the interannual variability of temperature in the area with the Atlantic sea surface temperature (SST) is also analysed, but SSTs do not show any significant predictive skill, and the statistically significant relationship does not seem to be causal.
\end{abstract}

KEY WORDS: Cantabrian · Iberian · Winter $\cdot$ Temperature $\cdot$ Variability

\section{INTRODUCTION}

The area and the 6 sites used in this paper (Fig. 1) were selected because of the steep meridional gradients of winter temperature and precipitation that occur, even though the spatial coverage is very low. This was long ago recognised using, for instance, classical regionalizations of climate such as Gorezynski's index (Font 1983a,b). Winter (DJF) precipitation and temperature change drastically from the 3 continental sites (Burgos, Logroño and Olite) to the 3 coastal ones (Santander, Sondika and Donostia). During the period 1950-1996, the average value of DJF precipitation (temperature) of the 3 continental sites was $121 \mathrm{~mm}$ $\left(5.2^{\circ} \mathrm{C}\right)$, while the average of the 3 coastal sites was $393 \mathrm{~mm}\left(9.3^{\circ} \mathrm{C}\right)$, the meridional distance from the continental to the coastal sites being about $120 \mathrm{~km}$. When

*E-mail: wdpsaagj@lg.ehu.es dealing with interannual climate variability, the northern coast of the Iberian Peninsula shows significant differences to the rest of the Iberian Peninsula. The spatial variability, as shown by the leading empirical orthogonal vectors (EOFs) of Iberian precipitation or temperature fields, shows low loading factors and steep gradients in this area.

This effect is especially relevant when analysing precipitation EOFs (Zorita et al. 1992, Fernández-Mills 1995, Rodríguez-Puebla et al. 1998, Serrano et al. 1999). Mediterranean and Cantabrian coasts show small loading factors in the leading EOF of precipitation. The uncoupled behaviour of precipitation of Mediterranean and Cantabrian coasts to the overall Iberian precipitation is also evident in some correlation analyses of teleconnection indices and local series (Rodó et al. 1997) and some downscaling studies (Biau et al. 1999). There are some works that discuss the characteristics of the Mediterranean coast (Rodó et al. 1997, Romero et al. 1998), while there is no work which 


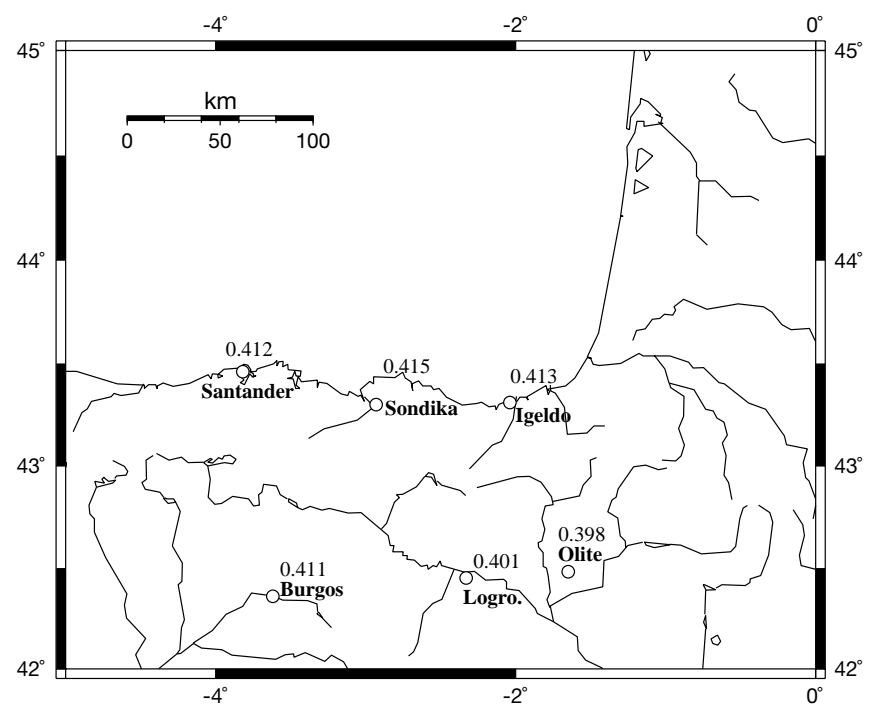

Fig. 1. Measurement sites and loading factors corresponding to the first unrotated empirical orthogonal function (EOF) of average winter (DJF) temperature in the area

specifically addresses the problem posed by the Cantabrian coast. The temporal variability of winter precipitation over the Cantabrian coast can be successfully explained by differences in baroclinic activity and effects of the orography on large-scale moisture transports.

The uncoupling of the Cantabrian coast is also clear when dealing with variability of winter temperature. The leading Varimax rotated EOF of winter temperature over the Iberian Peninsula, computed from 56 sites for the period 1949-1998, explains $31 \%$ of the total variance, and its spatial structure (Fig. 2) shows low loading factors on the Cantabrian coast.

In a previous work, the trends of several Spanish sites were analysed (Oñate \& Pou 1996). They performed a regionalization of the trends by means of multidimensional scaling analysis and cluster analysis. Their results show a different behaviour by the Cantabrian coast with respect to the rest of the Iberian Peninsula. However, they did not analyse the physical causes behind the differences.

From a global perspective, the area is placed in the transition zones which appear in wider analysis of correlation of surface air temperature with the major hemispheric teleconnection patterns (Hurrell 1995, 1996, Thompson \& Wallace 1998). The interannual variability of winter temperature in the area is not linked to any of these hemispheric patterns (North Atlantic Oscillation [NAO] and Arctic Oscillation [AO]), and in the Cantabrian coast the correlation with the NAO and AO is not significant, making the physical reasons that explain the variability of temperature during winter in this small area an interesting topic to study.

Analyses of the statistical correlation of temperature to atmospheric stationary circulation have already been conducted over a broader area. One of them used monthly data with the seasonal cycle removed (Corte Real et al. 1995). It shows a link of the temperature over a great part of the Mediterranean basin with a canonical vector of atmospheric circulation that resembles the East Atlantic (EA) teleconnection pattern (Wallace \& Gutzler 1981, Bell \& Halpert 1995). The analysis over the whole Mediterranean basin shows that, through the year, positive (negative) temperature anomalies of a great part of the western Mediterranean depend on the existence of a low (high) pressure centre located over the eastern North Atlantic (Maheras \& Kutiel 1999). However, this study only covered the southern area of the Iberian Peninsula. Similar results were obtained by analysis of the individual records of some sites (Lisbon, Madrid and Barcelona) on the Iberian Peninsula outside the area with low loading factors shown in Fig. 2 (Maheras et al. 1999).

Section 2 of the paper briefly describes the main characteristics of the data and the criteria involved in the selection of the 6 sites. A description of how a regional time series was derived by means of principal components analysis (PCA) is given in Section 3. Section 4 is devoted to the analysis, by means of correlation analysis, of the relationship between the temporal variability of winter temperature and the main atmospheric teleconnection patterns. Some physical explanations of the correlation found are given and it is shown that the synoptic scale transients are not relevant to the problem. In Section 5, the relationship between the regional temperature series and the Atlantic sea surface temperatures (SSTs) is studied,

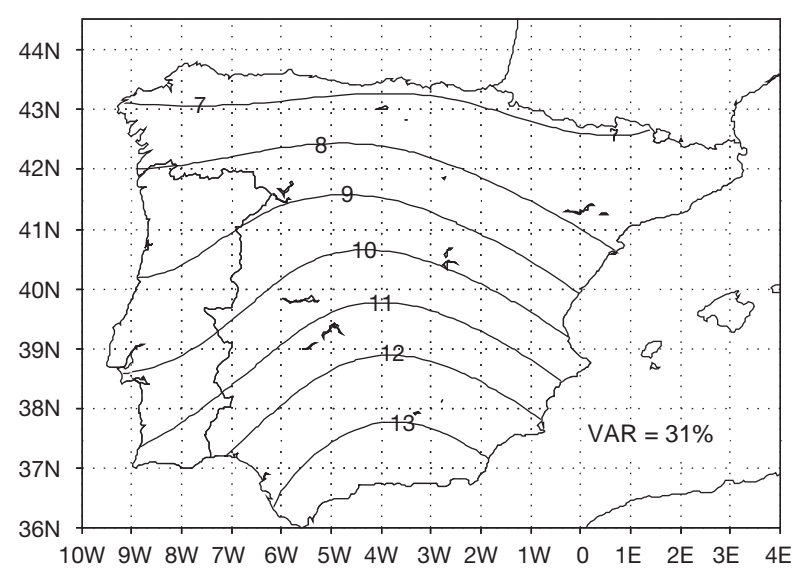

Fig. 2. Varimax rotated leading EOF of Iberian winter temperature 
and the results of this section are related to those of the previous one. Finally, the main conclusions of the work are discussed.

\section{THE DATA}

Fig. 1 shows the 6 sites employed in the study. They are placed within a small area, so that, with respect to the general atmospheric circulation, the climate factors related to position are almost the same for the complete set of observatories. With regard to other climate factors, such as continentality or topography, the sites behave differently. The sites have traditionally been classified (Font 1983a,b, García de Pedraza \& Reija 1994) as coastal (Santander, Sondika and Igeldo) and continental (Burgos, Logroño and Olite). Their selection was made in order to adequately sample continental and coastal behaviour. A zonal range of hills, approximately $1000 \mathrm{~m}$ high, occurs between the coastal and continental sites. These hills are evident in the way the rivers flow in Fig. 1. The hills are a barrier to meridionally oriented flows in the area, causing strong Föhn effects during these meridional events. The cited references provide a thorough coverage of the descriptive climatology of the area.

Time series available in the area furnished by the Spanish Institute of Meteorology were used. The original series have very few missing values in the $47 \mathrm{yr}$ used in the study (1950-1996). All of the instrumental series are complete, except that for Olite, where 2 winters (1974 and 1996) are noted as missing. Those missing values were filled by means of multivariate linear regression with close sites. The regression coefficients were independently computed for each month.

To analyse the atmospheric circulation over the area, 2 different data sets were used. The first one is the set of temporal expansion coefficients of the Northern Hemisphere's $700 \mathrm{hPa}$ geopotential surface, with the eigenvectors defined by means of a Varimax rotated PCA (Bell \& Halpert 1995), available from NOAA's Climate Prediction Center (CPC) (http://www.cpc.ncep. noaa.gov/data/cddb/). For other parts of the work, the NCEP Reanalysis project's data were used (Kalnay et al. 1996). The data used in this work are a subset of the $6 \mathrm{~h}$ original reanalysis for a reduced domain available from the Climate Research Unit, University of East Anglia (http://www.cru.uea.ac.uk).

The data set used in the analysis of the interannual variability of winter SSTs is the Global Ocean Surface Temperature Atlas 8 (GOSTA-8) data set, distributed on CD-ROM and edited by the Massachusetts Institute of Technology (MIT), the United Kingdom Meteorological Ofice (UKMO) and the Physical Oceanography Distributed Active Archive Center (PODAAC). It is based on the UKMO's MOHSST6 data set, which is also the basis of GISST 2.2 and incorporates bucket corrections. Extensive documentation on this data set has been published elsewhere (Parker et al. 1994, Folland \& Parker 1995). Unlike GISST 2.2, GOSTA-8 is not interpolated to a $1 \times 1$ grid, nor are the missing values filled by means of any procedure. This means that on the correlation maps the number of degrees of freedom will not be constant for all the grid cells.

\section{DEFINITION OF A REGIONAL WINTER TEMPERATURE TIME SERIES}

After detrending the original series, no significant inhomogeneity appears to a 95\% confidence level for any of the stations according to Alexandersson's SNHT (Standard Normal Homogeneity Test) shift test (Alexandersson 1986, Alexandersson \& Moberg 1997). The trends (computed as linear regressions: $T_{t}=a_{0}+a_{1} t$, with $T_{t}$ being the winter temperature at each site and $t$ time) were removed prior to any other analysis (Table 1). Table 1 also shows the probability (as \%) of obtaining by chance the same trend, according to a Student's $t$-test on the correlation coefficient of the linear model for each site. Similar results on the sign and significance of the series are obtained using the nonparametric Kendall test.

With the exceptions of those for Logroño and Olite, the trends are very consistent from site to site, on the order of $0.03 \mathrm{~K} \mathrm{yr}^{-1}$. In some cases, these trends are consistent with those found at nearby sites (EstebanParra et al. 1995). However, they are too high when compared with other global series (Ghil \& Vautard 1991, Pielke et al. 1998, Angell 1999). Though no exact numeric values are available, the present trends may be of the same order as the one presented in the IPCC report winter maps (Nicholls et al. 1996). The differences with global series might be due either to the reference period used to compute the trend, to the different spatial domains or simply to the fact that in this area trends reflect urbanisation and land-use changes,

Table 1. Trends of winter temperature time series at each site and their respective probabilities of being $0 .{ }^{*}$ Trends $95 \%$ significantly similar according to the nonparametric Kendall test

\begin{tabular}{|lcc|}
\hline Site & Trend $\left({ }^{\circ} \mathrm{C} \mathrm{yr}^{-1}\right)$ & Probability (\%) \\
\hline Burgos* & 0.0303 & 0.8 \\
Igeldo* & 0.0296 & 1.3 \\
Logroño & 0.0171 & 10.6 \\
Olite & 0.0203 & 6.9 \\
Santander & 0.0374 & 0.1 \\
Sondika* & 0.0252 & 3.1 \\
\hline
\end{tabular}


as most of the sites are close to populated areas. Further clarification of this point would require an extensive study of the influence of urbanisation on the temperature record in the area, which is not the purpose of this paper. Therefore, the trend will be discarded in the next sections, with the assumption that it is some kind of inhomogeneity or low-frequency noise unresolvable with the length of the record used (47 yr).

We used PCA of the correlation matrix as a way to reduce the dimensionality of the original data set to derive a single regional time series. It was clear from the correlation matrix that the spatial coverage of the leading mode of temperature variability is wider than the area analysed. The use of weighted averages to derive regional time series is a standard practice (Jones \& Hulme 1996). In this case, the use of PCA allows the derivation of weighting coefficients which meet the objective criteria that they form the leading eigenvector of the correlation matrix. The coefficients are shown in Fig. 1. The first unrotated principal component (PC) explains $92 \%$ of the variance of the data set. It does not show any significant degeneracy (North et al. 1982). It is stable, according to a Monte Carlo test based on the congruence coefficient (Richman \& Lamb 1985, Richman 1986, Cheng et al. 1995) between the eigenvectors of the complete sample (master eigenvector, $\vec{e}_{i}$ ) and the eigenvectors corresponding to random subsamples of $30 \mathrm{yr}$ (perturbed eigenvectors, $\vec{e}_{i}^{*}$ ). The first PC reflects the same variability as the average of the 6 series, because the correlation coefficient of these series is virtually one. However, the analysis performed on the structure of the eigenvalues of the correlation matrix allows us to confidently reject the possibility that any significant spatial variability exists in the area.

\section{LINKS TO GLOBAL TELECONNECTION PATTERNS}

\subsection{Methodology used in the correlation analysis}

It seems interesting to perform the correlation analysis at 2 time scales, the interannual and interdecadal parts of the signal. To achieve this, the time scales of

Table 2. Correlation coefficient of the unfiltered (raw) data and LF and HF components of $T_{1}$ (first principal component of temperature) with some teleconnection indices

\begin{tabular}{|lccc|}
\hline & Raw & LF & HF \\
\hline$\left|\mathrm{R}_{95}{ }\right|$ & 0.30 & 0.61 & 0.34 \\
$T_{1}-$ EA & 0.54 & 0.10 & 0.63 \\
\hline
\end{tabular}

variability in the area were separated using a Kolmogorov-Zurbenko $\mathrm{KZ}_{3,3}$ digital filter (Eskridge et al. 1997, Rao et al. 1997). Given the original time series $x_{t_{1}}$ low-passed and high-passed components are derived by means of the expressions $\operatorname{LF}\left(x_{t}\right)=\mathrm{KZ}_{3,3}\left[x_{t}\right]$ and $\mathrm{HF}\left(x_{t}\right)=x_{t}-\mathrm{KZ}_{3,3}\left[x_{t}\right]$. Those signals effectively reflect components whose periods are longer than approximately $8.5 \mathrm{yr}$ (LF component) or shorter than $8.5 \mathrm{yr}$ (HF component). In any case, it must be taken into account that the LF component has already been deformed by the removal of the trend of the original data.

The links of raw, HF and LF temperature components with global atmospheric teleconnection patterns obtained from the CPC were checked by means of correlation analysis. Previous work (Fraedrich \& Müller 1992, Rodó et al. 1997) shows that the El Niño/Southern Oscillation (ENSO) signal is very weak in winter in the area, so that it was not analysed further. Of all the indices obtained from the $\mathrm{CPC}$, the analysis was focused on the candidates that have the strongest influence on the climate of the area: East Atlantic (EA), East Atlantic/Western Russia, North Atlantic Oscillation, Polar Eurasia and Scandinavia patterns (Bell \& Halpert 1995).

It is clear that the filtering operation, mainly when dealing with LF components, will cause a significant decrease in the degrees of freedom to be used in the test of the significance of the correlation coefficient. In order to take into account this effect and the decrease in the degrees of freedom due to the original autocorrelation of the series, a Monte Carlo experiment was conducted. Synthetic $x$ and $y$ time series were created using a Mersenne-Twister random number generator (Matsumoto \& Nishimura 1998). After an initial spin-up period $(1000 \mathrm{yr}), 500000$ values were generated for each series. Each of them is a first-order Markov process, whose autocorrelation for lag 1 is the same as the maximum autocorrelation found in all segments of all the time series involved in the correlation analysis. The series was filtered using the same filters as the data, and the correlations of $47 \mathrm{yr}$ long segments (raw data) and $41 \mathrm{yr}$ long segments (filtered data) were computed. From the distribution of these correlation coefficients, numeric histograms and significance limits were obtained.

\subsection{Results from the correlation analysis with atmospheric teleconnection patterns}

Table 2 shows the correlation coefficients of the first PC of temperature in the area $\left(T_{1}\right)$ and the PCs corresponding to the EA teleconnection pattern. The correlation coefficient is much higher than the one found with NAO (Hurrell 1996) or AO (Thompson \& Wallace 


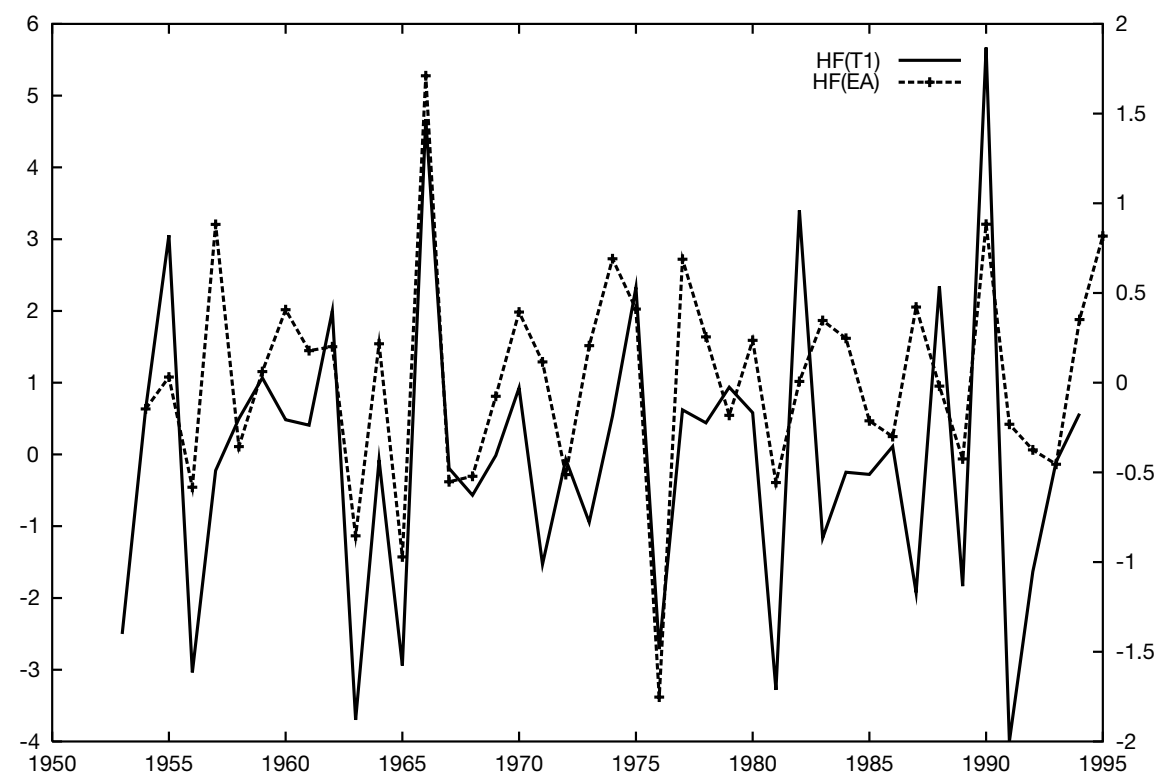

Fig. 3. High-pass components of the first principal component of temperature in the area $\left(T_{1}\right)$ and high-pass components of the EA index

1998), which are not significant. Correlation coefficients with other indices are not as high as with EA and they are not shown. Low-pass components are not significantly correlated to any of the tested indices, so that low-pass variability seems linked to other factors.

In order to check the stability of the correlations with time, running correlations using 32 yr long segments were computed. To get the $95 \%$ confidence levels for the correlation coefficient, the same Monte Carlo experiment as mentioned above was conducted, although 32 yr (raw data) and 26 yr long segments (filtered data) were used. EA's running correlations are very stable during the instrumental record. As an example, Fig. 3 shows the time series corresponding to the components. The existence of the correlation and its sign was also tested for the whole period and the running segments by means of Spearman's and Kendall's tests; they remain significant and of the same sign.

\subsection{Physical explanation of the correlation found}

The linear PCA model involved in the determination of the rotated EOFs of geopotential height that is used to compute the teleconnection indices at the CPC can be inverted, as usually done in factor analysis. Therefore, the geopotential height in each time instant can be expressed as $\Phi(\vec{r}, t)=\bar{\Phi}(\vec{r})+\sum_{i} c_{i}(t) \Phi_{i}(\vec{r})+\delta(\vec{r}, t)$, with $\Phi(\vec{r}, t)$ being the geopotential field at time $t, \bar{\Phi}(\vec{r})$ the average geopotential field during the period of reference climatology, $\Phi_{i}(\vec{r})$ the $i$ th EOF of the linearized model, $c_{i}(t)$ the corresponding $\mathrm{PC}$ and $\delta(\vec{r}, t)$ the error field at time $t$. This allows, disregarding the geostrophic flow from the geopotential error field $\delta(\vec{r}, t)$, one to compute a linearized decomposition of the geostrophic flow as $\vec{V}(\vec{r}, t)=\vec{V}(\vec{r})+\sum_{n} c_{n}(t) \vec{V}_{n}(\vec{r})$ with $\vec{V}(\vec{r})$ being the average geostrophic flow derived from the average geopotential height and $\vec{V}_{n}(\vec{r})=\frac{1}{f} \vec{k} \times \vec{\nabla} \Phi_{n}$ the geostrophic anomaly corresponding to a unit value of $c_{n}(t)$. This analysis is performed using winter data, without filtering in the interannual frequency band.

To check whether the linearized flow and the previous correlation analysis yield similar results, a 2dimensional regression model was created using the zonal and meridional enthalpy transport density vectors at $700 \mathrm{hPa}\left(H_{u}=C_{p} u T\right.$ and $\left.H_{V}=C_{p} V T\right)$ as independent variables and the local first PC of temperature as the predicted variable, that is, $T_{1}{ }^{*}=a_{u} H_{u}+a_{V} H_{V}$. The regression was prepared for each grid point in the NCEP/NCAR Reanalysis data using DJF averaged $\left(c_{p} \bar{u} \bar{T}, c_{p} \bar{V} \bar{T}\right)$ and eddy $\left(c_{p} \overline{u^{\prime} T^{\prime}}, c_{p} \overline{V^{\prime} T^{\prime}}\right)$ enthalpy transport density vectors computed from the $6 \mathrm{~h}$ Reanalysis fields. As usual, the overbar means DJF averaged values, while the prime means departure of the instantaneous $(6 \mathrm{~h})$ values from the time average.

For the DJF averaged enthalpy transport density vectors, Fig. 4a shows as contours the fractions of the variance of $T_{1}$ that can be accounted for by the linear model based on the enthalpy density fluxes in each 
grid point, whilst the arrows correspond to the unitary vectors defined by each pair $\left(a_{u}, a_{V}\right)$ of regression coefficients multiplied by the fraction of variance of the original $T_{1}$ series that can be accounted for by the linear regression model at each grid point. According to a simple $F$-test, contours higher than 0.25 are significant to $95 \%$. The spatial distribution of the correlation vectors closely resembles the geostrophic anomaly derived from EA's eigenvector (see corresponding figure in Bell \& Halpert 1995 or at http://www.cpc.ncep. noaa.gov/data/teledoc/eamap.gif). The correlation coefficients of the local $T_{1}$ series with the gridded geopotential heights at $700 \mathrm{hPa}$ (see Fig. 4b) show the same signature as those for EA and match closely the 2dimensional regression map with the enthalpy transport density vector. Thus, a positive EA pattern causes a southwestern flow over the study area. This means advection of southwestern warm air masses and a tem-

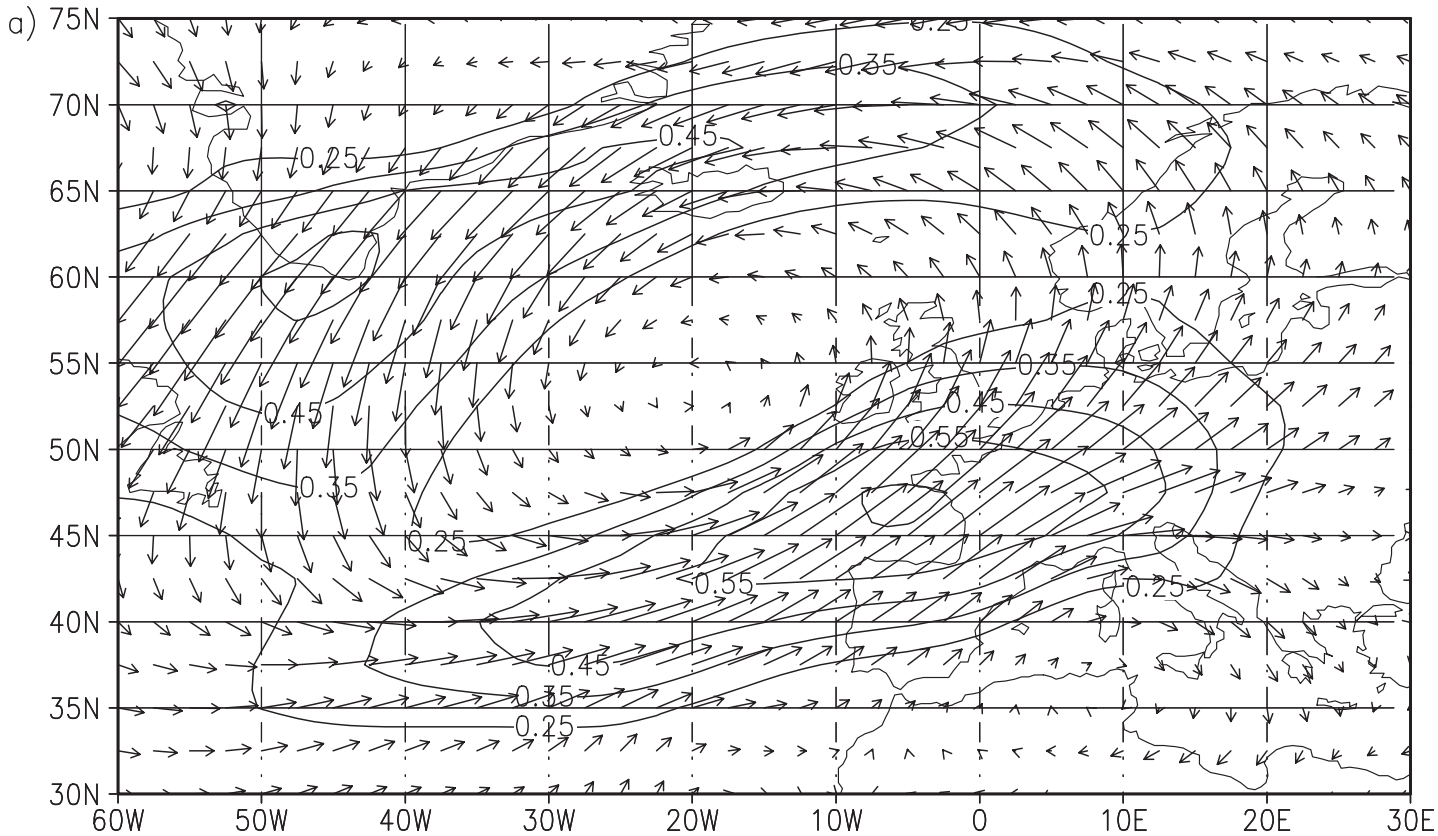

b) 75

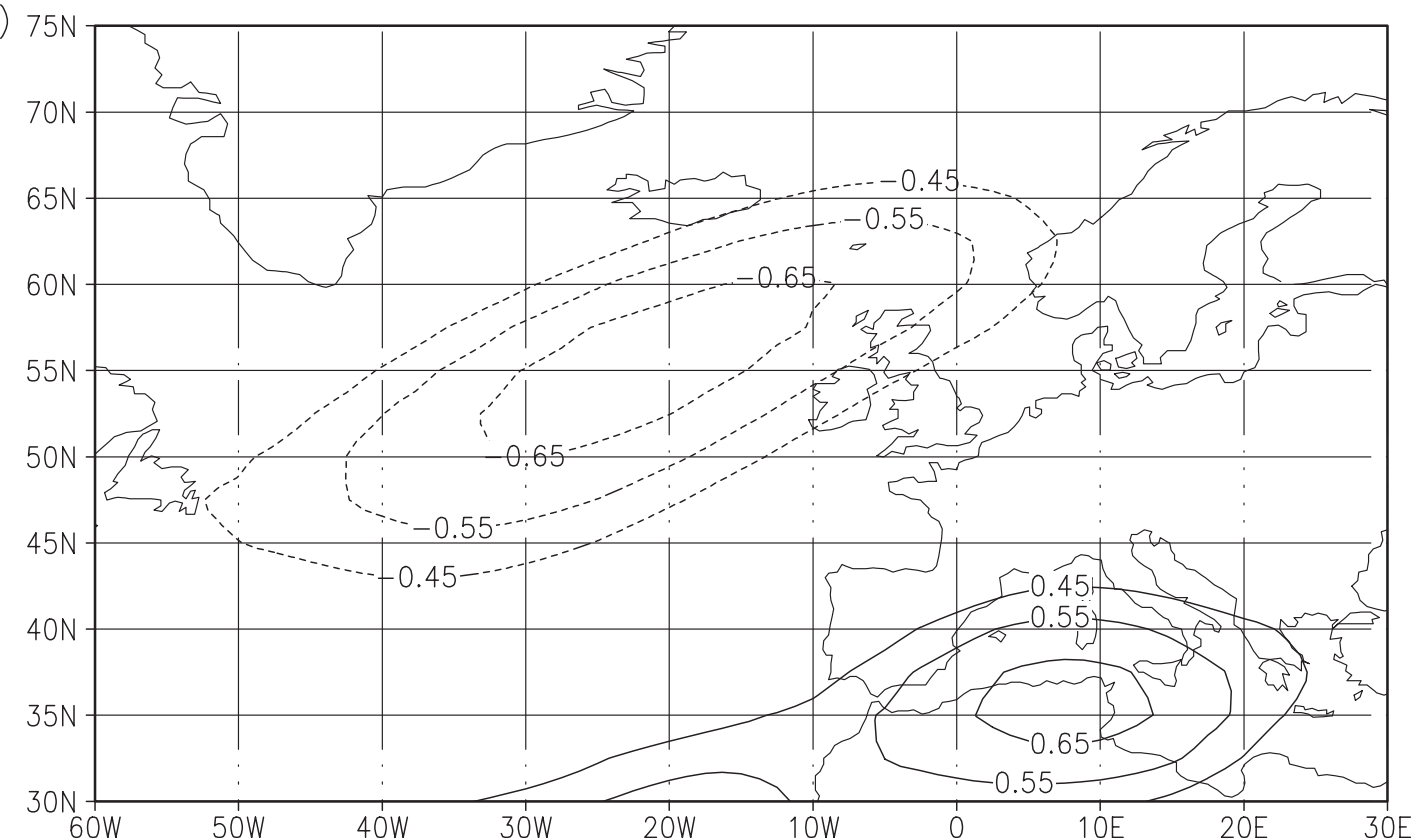

Fig. 4. (a) Regression map of $T_{1}$ and the gridded DJF averaged enthalpy transport density vectors at $700 \mathrm{hPa}$. (b) Correlation coefficient of $T_{1}$ and the DJF average of geopotential height of the $700 \mathrm{hPa}$ surface 
perature increase due to Föhn effects; the latter is due to the fact that these air masses must cross the Iberian Peninsula, with a significant ascent of air in mountain ranges as high as $2000 \mathrm{~m}$ to reach the study area. The results for $700 \mathrm{hPa}$ are shown to allow for an easy comparison to the EA eigenvectors at http://www. cpc.ncep.noaa.gov/data/teledoc/eamap.gif; the results were also computed at 850, 500, 300 and $200 \mathrm{hPa}$. The results for these levels are very similar to the ones at $700 \mathrm{hPa}$. This result, which links the stationary circulation to the temperature anomalies in the area, is in complete agreement with previous results by other authors (Corte Real et al. 1995, Maheras \& Kutiel 1999, Maheras et al. 1999).

The regression map computed from the eddy heat fluxes (Fig. 5a) explains a significantly lower part of the variance of $T_{1}$. Therefore, $T_{1}$ is linked to stationary flow, and not to the eddy part of the circulation (Hurrell \& van Loon 1997). The fact that eddy heat fluxes are irrelevant to the analysis of this problem is also evident from the correlation map of $T_{1}$ to the mean absolute deviation (MAD) of band pass filtered geopotential height of the $300 \mathrm{hPa}$ surface (Fig. 5b). This MAD was computed during each of the winters in the $6 \mathrm{~h}$ Reanalysis data by means of high pass $\mathrm{KZ}_{7,4}$ and low pass $\mathrm{KZ}_{3,3}$ filters, which yield cut off periods of 2 and $10 \mathrm{~d}$. The details of the filter used to determine the storm tracks do not have a strong impact on the determination of the position of the storm tracks (Blackmon et al. 1984, Wallace et al. 1988, Orsolini et al. 1998). There is not a significant change in synoptic activity over Southwestern Europe during anomalously warm/ cold periods. The geographically closest difference that appears in the correlation maps is placed over the Atlantic, which is a clear signature of the role of EA in determining the Atlantic storm tracks (Lau 1988, Rogers 1997) and supports previous correlation of temperature to EA.

\section{INFLUENCE OF ATLANTIC SEA SURFACE TEMPERATURE}

Previous works (Fraedrich \& Müller 1992, Rodó et al. 1997) show that the ENSO signal is weak in this area during winter, so that the influence of SST, if any, must originate in the Atlantic, tropical or not. To check this hypothesis, correlation maps of the first PC of winter temperature in the area and monthly SSTs over the Atlantic were computed. The correlation maps were computed for unfiltered and HF (Section 4.1) SST and $T_{1}$ data. Due to the detrending of the local time series, the computation of the LF maps was not performed. To check for the existence of lead/lag relationships, several correlation maps were computed for each of the frequency bands, with up to 6 mo of lead/lag SST data with respect to the corresponding winter, though only the most interesting conclusions are presented. The number of temporal degrees of freedom entering each of the cells is not constant due to the presence of missing data in the original SST data set. Therefore, grid cells with less than $30 \mathrm{yr}$ of valid data were tagged as missing and do not appear in the maps. Correlation coefficients in the interval $[-30,30]$ are not shown to enhance the image. The correlation coefficients shown correspond to the 90-95\% limit, depending on the temporal degrees of freedom entering each grid value, which range from 30 to 41 .

The first conclusion is that correlation shapes show spatially similar patterns when analysing HF and unfiltered maps, but correlations are more intense on HF maps than on unfiltered ones (not shown). There is no clear correlation (neither simultaneous nor lagged) with SSTs in the tropical Atlantic Ocean for HF maps, and only the extratropical Atlantic is shown. The correlations on HF maps are higher for SST data that lag the atmospheric signal by 1 mo (compare Figs. $6 \& 7$ ). This can be related to the fact, already pointed out by other researchers, that on these time scales the extratropical Atlantic SST may be mainly driven by atmospheric circulation through the latent and sensible heat fluxes from the ocean to the atmosphere, tropical SSTs being the main forcing factor of the extratropical atmospheric variability (Webster 1981, Frankignoul 1985, Wallace et al. 1990, Cayan 1992a,b, Luksch \& von Storch 1992, Graham et al. 1994, Battisti et al. 1995, Druffell 1997, Lau 1997). There does not appear to be such clear lead/lag relationships on the LF maps (not shown), where the role of extratropical SSTs may be more important (Kushnir 1994). However, the detrending of the temperature series already reduced the variance of this LF component of the signals.

\section{CONCLUSIONS}

The first PC of the winter (DJF) temperature of the area captures the interannual variability common to the 6 sites well, and, due to the different local climate factors in the area, this PC must primarily reflect synoptic-scale variability.

There are marked correlations of unfiltered and high-pass components of the first PC of temperature in the area with the PC corresponding to the EA teleconnection pattern. The correlation of local temperature with EA is higher than other common correlations cited in the Northern Hemisphere, such as the one of temperature with the NAO index, which is not significant in our study area. This result is in close agreement with previous results for different areas of Southwestern 
Europe (Corte Real et al. 1995, Maheras \& Kutiel 1999, Maheras et al. 1999).

The correlation shown can be satisfactorily explained based on the average enthalpy transport density vectors caused by the EA pattern and this result appears for the geopotential fields too. Eddy terms do not apparently influence the variability of winter temperature over the area.
The structure of the lagged correlation maps of winter temperature in the area with the Atlantic sector's SST is consistent with the interpretation that, in periods shorter than $7 \mathrm{yr}$, the average atmospheric circulation drives SST anomalies in the Atlantic basin through the latent and sensible heat fluxes. The link of the Atlantic SST anomalies to temperatures, although statistically significant, does not seem causal.
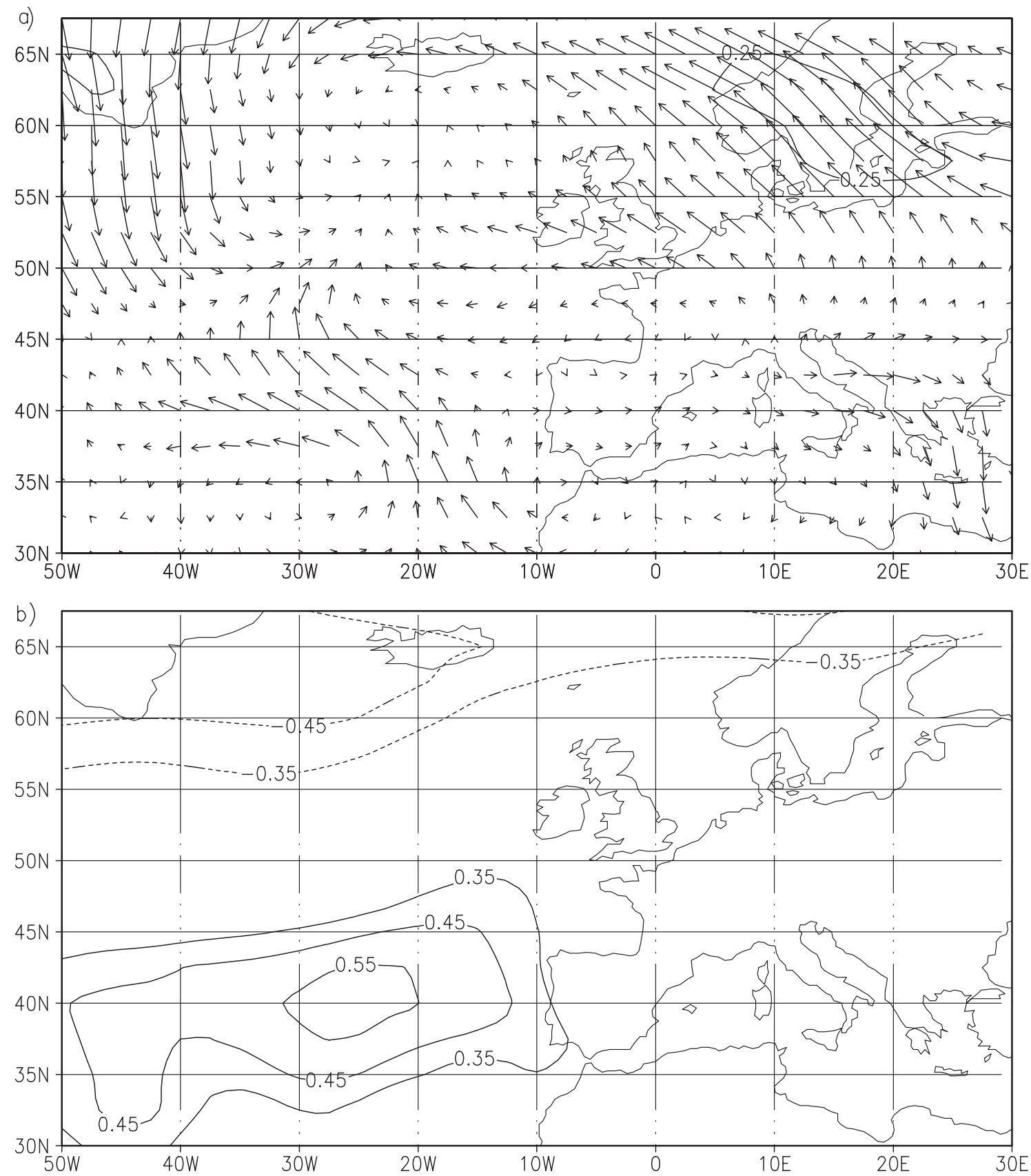

Fig. 5. (a) Regression map of $T_{1}$ and the gridded DJF averaged eddy enthalpy transport density vectors at $700 \mathrm{hPa}$. (b) Correlation coefficient of $T_{1}$ and the DJF mean absolute deviation of synoptic band pass filtered geopotential height of the $300 \mathrm{hPa}$ surface 


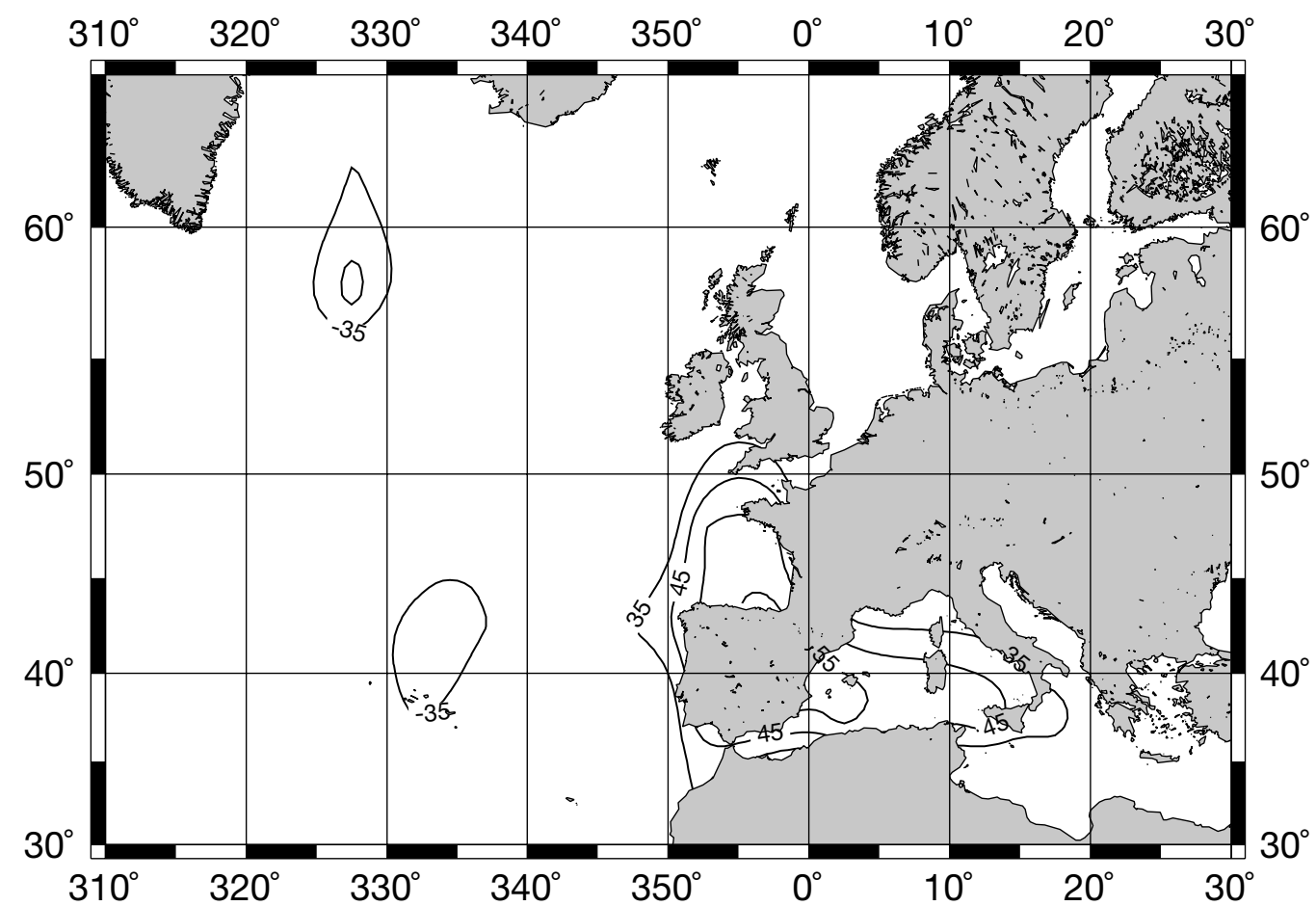

Fig. 6. Correlation coefficient (\%) of high-pass SST data (January) and the first PC of DJF temperature

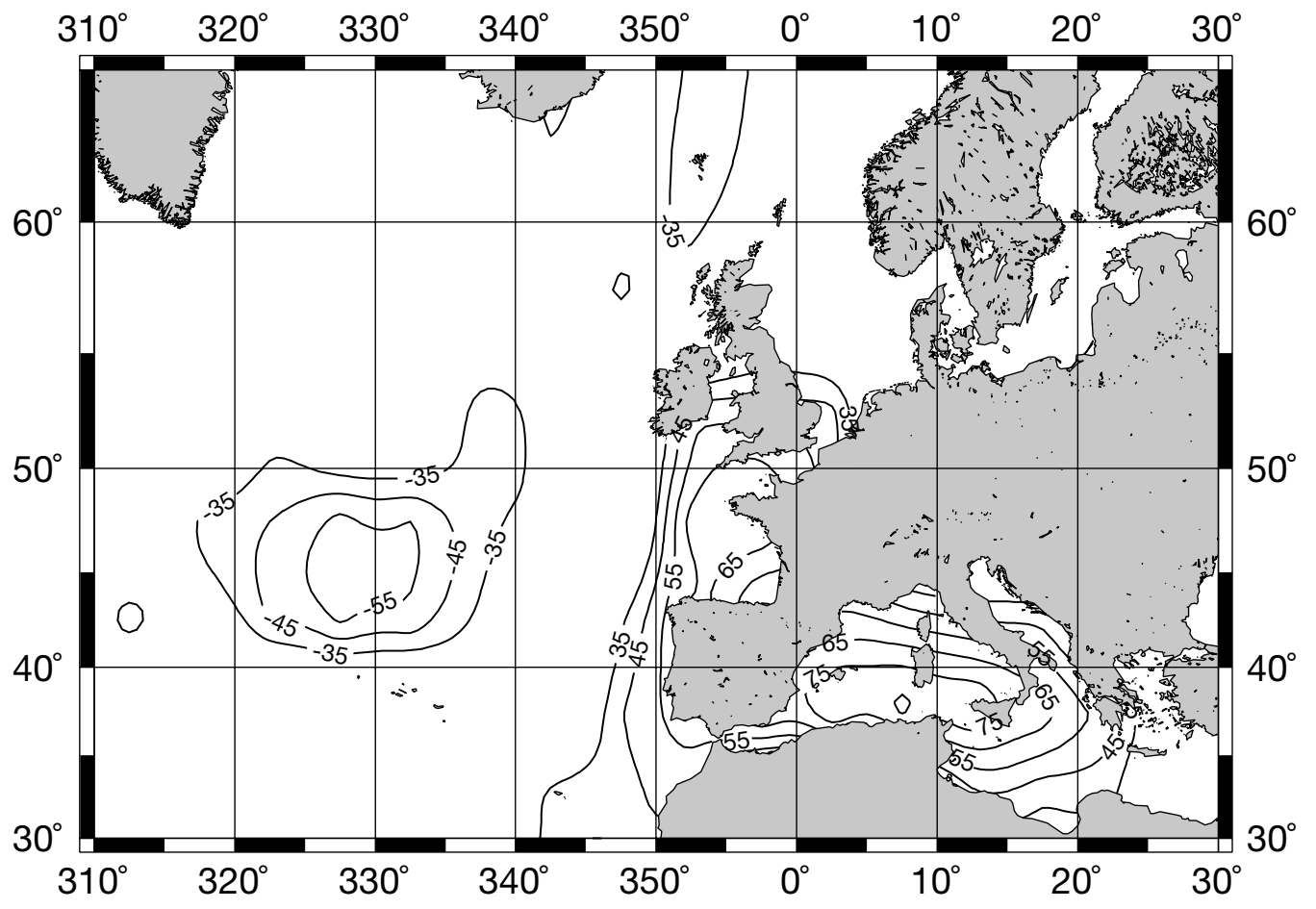

Fig. 7. Correlation coefficient (\%) of high-pass SST data (February) and the first PC of DJF temperature 
Acknowledgements. This work was possible thanks to grants CLI98-0236 (Plan Nacional de I+D-CICYT) and UPV060.310G16/98. The Spanish Institute of Meteorology (INM) kindly provided the data used in the study. Comments by 2 anonymous referees considerably improved the first version of this manuscript. The Sea Surface Temperature data set was obtained from the NASA Physical Oceanography Distributed Active Archive Center at the Jet Propulsion Laboratory/California Institute of Technology.

\section{LITERATURE CITED}

Alexandersson H (1986) A homogeneity test applied to precipitation data. J Climatol 6:661-675

Alexandersson H, Moberg A (1997) Homogenization of Swedish temperature data. Part I: Homogeneity test for linear trends. Int J Climatol 17:25-34

Angell JK (1999) Comparison of surface and tropospheric temperature trends estimated from a 63-station radiosonde network, 1958-1998. Geophys Res Lett 26: 2761-2764

Battisti DS, Bhatt US, Alexander MA (1995) A modelling study of the interannual variability in the wintertime North Atlantic Ocean. J Clim 8:3067-3083

Bell GD, Halpert MS (1995) NOAA atlas No. 12. Interseasonal and interannual variability: 1986 to 1993. Climate Analysis Center, US National Oceanic and Atmospheric Administration, Camp Springs, MD

Biau G, Zorita E, von Storch H, Wackernagel H (1999) Estimation of precipitation by kriging in the EOF space of the sea level pressure field. J Clim 12:1070-1085

Blackmon ML, Lee YH, Wallace JM (1984) Horizontal structure of $500 \mathrm{mb}$ height fluctuations with long, intermediate and short time scales. J Atmos Sci 41:961-979

Cayan DR (1992a) Latent and sensible heat flux anomalies over the northern oceans: driving the sea surface temperature. J Phys Oceanogr 22:859-881

Cayan DR (1992b) Latent and sensible heat flux anomalies over the northern oceans: the connection to monthly atmospheric circulation. J Clim 5:354-369

Cheng X, Nitsche G, Wallace JM (1995) Robustness of lowfrequency circulation patterns derived from EOF and rotated EOF analyses. J Clim 8:1709-1713

Corte Real J, Zhang X, Wang X (1995) Large-scale circulation regimes and surface climatic anomalies over the Mediterranean Int. J Climatol 15:1135-1150

Druffell ERM (1997) Pulses of rapid ventilation in the North Atlantic surface ocean during the past century. Science 275:1454-1457

Eskridge RE, Ku JY, Rao ST, Porter PS, Zurbenko IG (1997) Separating different scales of motion in time series of meteorological variables. Bull Am Meteorol Soc 78: 1473-1483

Esteban-Parra MJ, Rodrigo FS, Castro-Díez Y (1995) Temperature trends and change points in the northern Spanish plateau during the last 100 years. Int J Climatol 15: 1031-1042

Fernández-Mills G (1995) Principal component analysis of precipitation and rainfall regionalization in Spain. Theor Appl Climatol 50:169-183

Folland CK, Parker DE (1995) Correction of instrumental biases in historical sea surface temperature data. Q J R Meteorol Soc 121:319-367

Font I (1983a) Atlas climático de España. Instituto Nacional de Meteorología, Madrid

Font I (1983b) Climatología de España y Portugal. Instituto
Nacional de Meteorología, Madrid

Fraedrich K, Müller K (1992) Climate anomalies in Europe associated with ENSO extremes. Int J Climatol 12:25-31

Frankignoul C (1985) Sea surface temperature anomalies, planetary waves, and air-sea feedback in the middle latitudes. Rev Geophys 23:357-3905

García de Pedraza L, Reija A (1994) Tiempo y clima en España. Meteorología de las Autonomías. DOSSAT-2000

Ghil M, Vautard R (1991) Interdecadal oscillations and the warming trend in global temperature time series. Nature 350:324-327

Graham NE, Barnett TP, Wilde R, Ponater M, Schubert S (1994) On the roles of tropical and midlatitude SSTs in forcing interannual to interdecadal variability in the winter northern hemisphere circulation. J Clim 7:1416-1441

Hurrell JW (1995) Decadal trends in the North Atlantic Oscillation: regional temperatures and precipitation. Science 269:676-679

Hurrell JW (1996) Influence of variations in extratropical wintertime teleconnections on Northern Hemisphere temperature. Geophys Res Lett 23:665-668

Hurrell JW, van Loon H (1997) Decadal variations in climate associated with the North Atlantic Oscillation. Clim Change 36:301-326

Jones PD, Hulme M (1996) Calculating regional climatic time series for temperature and precipitation: methods and illustrations. Int J Climatol 16:361-377

Kalnay E \& 21 others (1996) The NCEP/NCAR 40-year reanalysis project. Bull Am Meteorol Soc 77:437-471

Kushnir Y (1994) Interdecadal variations in North Atlantic sea surface temperature and associated atmospheric conditions. J Clim 7:141-157

Lau NC (1988) Variability of the observed midlatitude storm tracks in relation to low-frequency changes in the circulation patterns. J Atmos Sci 45:2718-2743

Lau NC (1997) Interactions between global SST anomalies and the midlatitude atmospheric circulation. Bull Am Meteorol Soc 78:21-33

Luksch U, von Storch H (1992) Modeling the low-frequency sea surface temperature variability in the North Pacific. J Clim 5:893-906

Maheras P, Kutiel H (1999) Spatial and temporal variations in the temperature regime in the Mediterranean and their relationship with circulation during the last century. Int Climatol 19:745-764

Maheras P, Xoplaki E, Davies T, Martín-Vide J, Barriendos M, Alcoforado MJ (1999) Warm and cold monthly anomalies across the Mediterranean basin and their relationship to circulation; 1860-1990. Int J Climatol 19:1697-1715

Matsumoto M, Nishimura T (1998) A 623-dimensionally equidistributed uniform pseudorandom number generator. ACM Trans Model Comput Simul 8:3-30

Nicholls N \& 107 others (1996) Observed climate variability and change. In: Houghton \& 5 others (eds) Climate change 1995: the science of climate change, Chap 3. Cambridge University Press, Cambridge, p 133-192

North GR, Bell TL, Cahalan RF, Moeng FJ (1982) Sampling errors in the estimation of empirical orthogonal functions. Mon Weather Rev 110:699-706

Oñate JJ, Pou A (1996) Temperature variations in Spain since 1901: a preliminary analysis. Int J Climatol 16:805-815

Orsolini YJ, Stephenson DB, Doblas-Reyes FJ (1998) Storm track signature in total ozone during Northern Hemisphere winter. Geophys Res Lett 25:2413-2416

Parker DE, Jones PD, Folland CK, Bevan A (1994) Interdecadal changes of surface temperature since the late nineteenth century. J Geophys Res 99:14373-14399 
Pielke RA, Eastman J, Chase TN, Knaff J, Kittel TGF (1998) 1973-1996 trends in depth-averaged tropospheric temperature. J Geophys Res 103:16927-16933

Rao ST, Zurbenko IG, Neagu R, Porter PS, Ku JY, Henry RF (1997) Space and time scales in ambient ozone data. Bull Am Meteorol Soc 78:2153-2166

Richman MB (1986) Rotation of principal components. J Climatol 6:293-335

Richman MB, Lamb PJ (1985) Climatic pattern analysis of three- and seven-day summer rainfall in the central united states: some methodological considerations and a regionalization. J Clim 24:1325-1343

Rodó X, Baert E, Comin FA (1997) Variations in seasonal rainfall in Southern Europe during the present century: relationships with the North Atlantic Oscillation and the El Niño-Southern Oscillation. Clim Dyn 13:275-284

Rodríguez-Puebla C, Encinas AH, Nieto S, Garmendia J (1998) Spatial and temporal patterns of annual precipitation variability over the Iberian Peninsula. Int J Climatol 18:299-316

Rogers JC (1997) North Atlantic storm track variability and its association to the North Atlantic Oscillation and climate variability of northern Europe. J Clim 10:1635-1647

Romero R, Guijarro JA, Ramis C, Alonso S (1998) A 30-year (1964-1993) daily rainfall data base for the Spanish

Editorial responsibility: Mike Hulme,

Norwich, United Kingdom
Mediterranean regions: first exploratory study. Int J Climatol 18:541-560

Serrano A, García JA, Mateos VL, Cancillo ML, Garrido J (1999) Monthly modes of variation of precipitation over the Iberian Peninsula. J Clim 12:2894-2919

Thompson DJ, Wallace JM (1998) The Artic Oscillation signature in the wintertime geopotential height and temperature fields. Geophys Res Lett 25:1297-1300

Wallace JM, Gutzler DS (1981) Teleconnections in the geopotential height field during the Northern Hemisphere winter. Mon Weather Rev 109:784-812

Wallace JM, Lim GH, Blackmon ML (1988) Relationship between cyclone tracks, anticyclone tracks and baroclinic waveguides. J Atmos Sci 45:439-462

Wallace JM, Smith C, Jiang Q (1990) Spatial patterns of atmosphere-ocean interaction in the northern winter. J Clim 3:990-998

Webster PJ (1981) Mechanisms determining the atmospheric response to sea surface temperature anomalies. J Atmos Sci 38:554-571

Zorita E, Kharin V, von Storch H (1992) The atmospheric circulation and sea surface temperature in the North Atlantic area in winter: their interaction and relevance for Iberian precipitation. J Clim 5:1097-1108

Submitted: November 29, 1999; Accepted: August 29, 2000 Proofs received from author(s): December 13, 2000 